\title{
O ENSINO DE GEOGRAFIA NOS ANOS INICIAIS DO ENSINO FUNDAMENTAL ${ }^{1}$
}

\author{
Alana Rigo Deon ${ }^{2}$ \\ (Dhttps://orcid.org/0000-0002-5930-6368 \\ Helena Copetti Callair \\ (1Dhttps://orcid.org/0000-0001-8043-659X
}

Resumo: Ensinar geografia desde os anos iniciais do ensino fundamental é uma oportunidade de fazer a relação entre os conteúdos tematizados e o mundo da vida. Para isso, problematizamos a ideia dos círculos concêntricos que tradicionalmente tem sido trabalhada nos anos iniciais, e apresentamos uma proposição que diz de considerar o lugar interligado ao contexto do mundo. A proposição é abordar os conteúdos destinados à disciplina de geografia considerando a escala de análise geográfica. A reflexão apresentada é de abordagem qualitativa e bibliográfica referenciada em autores da geografia e da educação e é sustentada pela teoria críticahermenêutica.

Palavras-chave: Estudo do lugar. Conceitos. Escala de análise. Mundo da vida. Conteúdos Escolares.

${ }^{1}$ Texto escrito com apoio da Agência de Fomento Fapergs, edital 02/2017 - Programa Pesquisador Gaúcho

2 Doutoranda em Educação nas Ciências pela Universidade Regional do Noroeste do Estado do Rio Grande do Sul. E-mail: alanardeon@gmail.com

3 Doutora em Geografia pela Universidade de São Paulo. Professora da Universidade Regional do Noroeste do Estado do Rio Grande do Sul. E-mail: helena@unijui.edu.br 


\section{GEOGRAPHY TEACHING IN THE EARLY YEARS OF ELEMENTARY SCHOOL}

Abstract: Teaching Geography since the early years of elementary school is an opportunity of making the relationship between the thematic contents and real life. For that reason, we problematize the idea of concentric circles that have traditionally been developed in the early years of elementary school, and we present a suggestion, which connects the place to the real-life context. So, this model will approach the contents that belong to the Geography discipline considering the scale of analysis. The presented reflection is a qualitative and bibliographic approach based on authors from the Geography and Education areas and it is supported by the Critical-Hermeneutic Theory.

Keywords: Study of the place. Concepts. The scale of analysis. Real-life context. School Contents.

\section{LA ENSEÑANZA DE LA GEOGRAFíA EN LOS AÑOS INICIALES DE LA EDUCACIÓN FUNDAMENTAL}

Resumen: Enseñar geografía desde los años iniciales de la educación fundamental es una oportunidad de hacer la relación entre los contenidos tematizados y el mundo de la vida. Para eso, problematizamos la idea de los círculos concéntricos que tradicionalmente ha sido trabajada en los años iniciales, y, presentamos una propuesta que aboga por considerar el lugar Inter ligado al contexto del mundo. La propuesta es abordar los contenidos destinados a la geografía, considerando la escala de análisis. La reflexión presentada es de un enfoque cualitativo y bibliográfico referenciada en autores de la geografía y de la educación, además de estar sustentada por la teoría crítica-hermenéutica.

Palabras clave: Estudio del lugar. Conceptos. Escala de análisis. Mundo de la vida. Contenidos Escolares. 


\section{Introdução}

Pensar a geografia nos anos iniciais remete a buscar os entendimentos de como a alfabetização geográfica ${ }^{4}$ pode fortalecer o processo de observar e compreender 0 mundo da vida, na medida em que a criança vai aprendendo a ler e a escrever, fazendo em consonância com isso, a leitura e a escrita de questões que são significativas para a vida humana. Este é o nosso entendimento de ter na geografia um componente curricular que contribui com 0 processo de alfabetização ${ }^{5}$ buscando perceber a realidade do mundo em que vivemos. E assim, dando as bases, para que as crianças desenvolvam o olhar crítico sobre 0 mundo, num processo que estimula 0 desenvolvimento da curiosidade para tornar interessante 0 aprendizado e ser significativo para a sua vida. Ressaltamos que não é o caso de facilitar o processo de aprendizagem, pois estudar exige esforço e aprender pode ser cada vez mais significativo se considerar o sujeito como um todo nesse processo, que tem além do intelecto um conjunto de elementos como a capacidade de observar, perceber, sentir, imaginar que são características dos seres humanos que podem ser aprimoradas pelo processo de ensino e aprendizagem.

Abordamos neste texto, a geografia nos anos iniciais com base nos fundamentos a respeito da vida, do conhecimento de um modo geral e, singularmente, pensando as políticas educacionais no contexto atual. Para isso, nos referimos à BNCC - Base Nacional Comum Curricular, que apresenta neste momento da educação brasileira as orientações para os currículos do ensino básico em todos os níveis. Com sustentação em autores da geografia e da educação nos dedicamos a uma reflexão acerca dos anos iniciais de Ensino Fundamental, em um contexto em que as formalidades do processo de avaliação da educação básica em nível global assumem um caráter formal. Acrescenta-se a isso, o olhar como acontece o ensino, e como se dá a formação dos professores para o trabalho com esse nível da educação, pelas proposições que têm sido adotadas nas escolas e pelas observações realizadas nas pesquisas que elaboramos confluindo para a reflexão aqui apresentada.

\footnotetext{
4 Segundo (GONÇALVES, 2013, p. 71) a alfabetização geográfica pondera sobre o "propósito da geografia escolar destinado aos estudantes do $1^{\circ}$ ao $5^{\circ}$ ano, ou seja, os anos iniciais do ensino fundamental. Ela é a "possibilidade do educando estar envolvido com conceitos e habilidades geográficas desde o início do seu processo de escolarização [...]"

${ }^{5}$ Segundo a BNCC o processo de alfabetização nos anos iniciais “[...] deve ser o foco da ação pedagógica. Afinal, aprender a ler e escrever oferece aos estudantes algo novo e surpreendente: amplia suas possibilidades de construir conhecimentos nos diferentes componentes, por sua inserção na cultura letrada, e de participar com maior autonomia e protagonismo na vida social" (BRASIL, 2018, p. 63).
} 
Iniciamos com a apresentação do que é a geografia, no seu âmbito de ciência e na disciplina escolar, quais os conceitos, princípios e categorias que a referenciam e caracterizamos como é a proposição para a geografia nos anos iniciais. A seguir, buscamos na BNCC as propostas e orientações para a geografia escolar no seu aspecto geral, e especificamente para este nível de ensino. A discussão referente à geografia e a formação para a cidadania sustenta as nossas reflexões, tendo como fundamento o interesse em pensar a formação humana numa perspectiva de formação do cidadão. Um sujeito cidadão é aquele que conhece a sua realidade e que adquire aportes teóricos para compreender o mundo para além limites da sua vida cotidiana. Neste caminho, os conceitos de local e global sustentam os estudos do lugar e do cotidiano, que são estes, os espaços de vivência dos alunos. E, por meio da escala de análise, propomos a ligação dos princípios e categorias para construção dos conceitos abordando os conteúdos definidos para esta etapa do ensino. Entendemos que cabe aos anos iniciais esboçar o que seja o processo de escolarização estabelecendo as bases para sustentação de todo o processo educacional do Ensino Fundamental e do Ensino Médio.

\section{O que é a geografia? A ciência e a disciplina escolar}

A geografia tem no espaço geográfico o seu objeto de estudo, e para ser compreendido em seu movimento, o espaço é tido como palco e ator. Palco, por ser o lugar onde acontecem os diversos movimentos (sociais, políticos, econômicos, naturais, culturais). E ator, pois possibilita ou desfavorece a realização de transformações pela sociedade e mesmo, da própria natureza nos mais distintos tempos e espaços. Assim que, as paisagens são a representação visível destes movimentos. E os conceitos de tempo e espaço são categorias fundantes para superar os reducionismos que fragmentam o físico e o humano, a natureza e a sociedade em âmbito da geografia.

Os conceitos da geografia são as ferramentas intelectuais para realizar as leituras de mundo e, portanto, para a construção do conhecimento com as crianças, possibilitando-lhes que o mundo seja entendido não apenas como lugar da experiência vivida, mas como um objeto de pensamento. Para Young (2011), a escola precisa ser o lugar onde ocorre o confronto entre os conhecimentos do mundo da vida com os conteúdos escolares, que permitem tematizar esse mundo. Para o autor é diferente, por 
exemplo, o entendimento da cidade como conceito da geografia e como lugar de experiência de vida dos sujeitos, pois “até certo ponto, é a mesma cidade, mas o relacionamento do aluno com ela, nos dois casos, não é o mesmo. A Londres onde vivem é um 'lugar de experiência”' (YOUNG, 2011, p.615). Londres como exemplo de uma cidade é um “objeto de pensamento" ou um "conceito".

A geografia, assim como as demais disciplinas escolares, reúne um conjunto de conceitos que permitem/possibilitam fazer a relação entre os conceitos cotidianos (aqueles adquiridos pela vivência da criança no mundo empírico/mundo da vida) com os conceitos teóricos (produzidos por pensadores e estudiosos que produzem conhecimentos). Para Young (2011, p. 615), os “conceitos cotidianos são 'captados' inconscientemente por todos em suas vidas diárias e são adquiridos pela experiência de formas ad hoc para propósitos específicos, relacionados com problemas particulares, em contextos particulares". E os conceitos teóricos “pertencem apenas a um mundo específico, constituído por pesquisadores especialistas envolvidos em desenvolver conhecimento novo" (YOUNG, 2011, p. 615).

Queremos encontrar os caminhos para estudar o lugar e as experiências dos estudantes de modo que eles construam um conhecimento a respeito, indo além do que vivem e observam no lugar das suas vidas. Por isso, como afirma Charlot (2009) os professores possuem duas tarefas pedagógicas fundamentais,

a primeira é ajudar os estudantes a administrarem o relacionamento entre os conceitos das diferentes disciplinas que constituem o currículo e seus referentes em suas vidas cotidianas. A segunda é apresentar aos alunos conceitos que têm significados que não derivam de sua experiência nem se relacionam diretamente com ela (CHARLOT, 2009 apud YOUNG, 2011, p. 616).

Os conceitos básicos da geografia: paisagem, território, região, lugar, além do conceito de espaço, que ao se aliar ao conceito de tempo são os meios teóricos que oportunizam pensar o mundo. 0 espaço é o conceito mais abrangente e mais abstrato da geografia, pois é nele que se materializam as formas, funções, estruturas e processos do mundo (SANTOS, 2014). O lugar é uma categoria de análise do espaço, que permite fazer o contraponto à perspectiva da globalização (CALLAI, 2005). A paisagem é o retrato dos diferentes lugares que compõem o espaço, é aquilo que enxergamos em nosso cotidiano (SANTOS, 1988). A região é um recorte do espaço que possui uma ligação com o conceito de paisagem, pois carrega consigo a dimensão física 
da paisagem, da cultura material e imaterial dos povos, que são marcas do seu processo histórico e natural (CALLAI, 2005; SANTOS, 1988). O território tem fundamentação em Heidrich e Heidrich (2010) e está ligado às relações de poder que são estabelecidas e que exercemos nos diferentes lugares, espaços e tempos.

$\mathrm{Na}$ geografia, cabe ainda considerar os princípios que tradicionalmente definem os rumos para a ciência geográfica e que amparam as pesquisas e suas interpretações e têm reflexos na disciplina escolar. Os princípios foram formulados a partir da pesquisa de campo pelos precursores da geografia científica ao longo da trajetória de sua constituição. A que nos servem hoje para pensar o ensino nos anos iniciais? Consideramos que este conjunto de princípios pode num exercício de interpretação indicar os caminhos para estudar geografia:

1. Princípio da localização: A manifestação de todo fenômeno é passível de ser delimitada; 2. Princípio da unidade terrestre: A terra é um todo, que só pode ser compreendido numa visão de conjunto; 3. Princípio da individualidade: Cada lugar tem uma feição, que the é própria e que não se reproduz de modo igual em outro lugar; 4. Princípio da atividade: Tudo na natureza está em constante dinamismo; 5 . Princípio da conexão: Todos os elementos da superfície terrestre e todos os lugares se interrelacionam; 6. Princípio da comparação: A diversidade dos lugares só pode ser apreendida pela contraposição da individualidade; 7. Princípio da extensão: Todo fenômeno manifesta-se numa porção variável do planeta ${ }^{6}$ (MORAES, 2000, p. 42-43, grifo nosso).

Assim, no exemplo do estudo de uma cidade podemos inferir que ela está localizada num determinado ponto do espaço, que pode ser dimensionado pelas coordenadas geográficas, que têm os limites que definem os bairros, que estabelecem a área urbana em relação à área rural, e que separa o município que acolhe a cidade dos demais municípios com quem faz a fronteira. Mas a cidade, não está separada, segregada dos demais espaços, pois faz parte de um conjunto unitário que é a terra e das relações que nela se estabelecem, faz com que os fenômenos localizados tenham inter-relação com o todo, pois cada lugar é parte integrante de um todo. Por outro lado, cada cidade tem suas marcas e caraterísticas que a singulariza, que the dá a identidade e a diferencia de outras ao mesmo tempo que tudo se movimenta, seja a natureza seja

\footnotetext{
${ }^{6}$ A geografia tem em sua trajetória de constituição como ciência, a descrição da terra, do mundo, da humanidade, por autores diversos. Com base nisso foram elaborados princípios que pretendem demarcar os caminhos da sua especificidade. Optamos por trabalhar aqui os princípios tratados por Moraes (2000) que são apresentas em sua obra "Geografia: pequena história crítica". Fica claro, no entanto, que essa opção não descarta as demais elaborações apresentadas por autores variados, mesmo porque todos que discutem os princípios da geografia tem em si aquilo que demarca esta especificidade (da Geografia) de olhar e pensar os problemas do mundo.
} 
os homens, seja na produção e organização dos espaços que têm em si os movimentos sociais. A conexão entre os fenômenos estabelece a relação entre os lugares e os fenômenos que se estendem pelo espaço, não são separados necessariamente em função dos limites e fronteiras.

Mas, o que isso interessa para estudar geografia pelas crianças que estão nos processos de alfabetização, aprendendo a ler e a escrever? E como os professores podem fazer para ensinar geografia sem que os fenômenos espaciais (que fazem parte dos conteúdos específicos dessa disciplina) sejam trabalhados de forma fragmentada?

\section{A geografia nos anos iniciais}

A geografia desde o início do ensino fundamental pode ser importante para que as crianças aprendam a fazer a leitura do mundo, iniciando pelo mundo da vida. Para Callai (2005) lemos o mundo antes de ler a palavra, isso quer dizer que antes mesmo da aprendizagem da leitura e da escrita, as crianças têm contato empírico com o mundo que está ao seu redor, e para isso utilizam mecanismos que são intuitivos como a observação e a percepção, pautadas pela sua curiosidade e imaginação. E, expressam por meio da linguagem primeiramente da fala e depois da escrita aquilo que observam e aprendem a conhecer. Palavras que podem ser escritas e lidas, para ler a realidade do mundo em que vivem. Não seriam palavras distantes ou imaginárias de uma situação qualquer, mas palavras que indicam as coisas que são parte do mundo e do lugar em que as crianças vivem e que podem colocar em jogo a relação entre os saberes prévios, as experiências propostas pelos professores e a formulação dos conceitos.

É nesse contexto que a alfabetização geográfica não fica apenas na palavra, mas no sentido que ela tem e expressa, e é aí que os processos de abstração permitem desenvolver a imaginação e construir entendimentos que vão além da escrita e da leitura de palavras. São palavras carregadas de sentido, seja pelo conceito que indicam, seja pela articulação com a imaginação, com os saberes prévios e as experiências vivenciadas. Essas que podem ser situadas no tempo e nos espaços, considerando-se os lugares em que acontecem e buscando as explicações para entender os porquês das coisas do mundo.

A alfabetização, neste sentido, inicia pelo olhar e reconhecimento das formas dos elementos que estão aparentes (expressas pelas paisagens) e que ao serem nominados, 
estão permeados pela dimensão do simbólico, que na relação com a abstração possibilitam construir os conceitos que remetem a partir dos conteúdos escolares. Assim, se coloca o mundo como objeto a ser desvendado, um mundo que compõem os conteúdos, que permite a construção dos conceitos como resultado do processo que leva o aluno a fazer a leitura e a escrita destas experiências retratadas em palavras e formas de pensamento.

Então, como os conteúdos da disciplina de geografia encaminham ao processo de alfabetização? Ao nosso entendimento, pela leitura do mundo e escrita de palavras que carregam em si os conceitos, e que tornam significativa a leitura e a escrita do mundo. Neste sentido, o lugar onde vive a criança se apresenta como o conteúdo e os pressupostos da geografia auxiliam para fazer o estudo do (deste) lugar. Tradicionalmente tem-se trabalhando na perspectiva dos círculos concêntricos, num processo linear em que o ensino parte do EU - (alunos) e vai sendo ampliado para a família, escola, rua, bairro, cidade, numa sucessão de espaços absolutos que fragmentam os espaços e a vida vivida e, assim, pois não apresentam possibilidades de inter-relação entre si. Essa afirmação se sustenta nas pesquisas que desenvolvemos, que abordam desde os princípios epistemológicos dessa interpretação do mundo pelos círculos concêntricos (KUHN, CALLAI, TOSO, 2019; TOSO, KUHN, CALLAI, 2018) até a verificação dos planos pedagógicos das disciplinas dos cursos de pedagogia e as proposições curriculares para este nível de ensino - anos iniciais do Ensino Fundamental?

As duas figuras a seguir indicam o trabalho realizado em geografia, sendo a primeira apresentando os círculos concêntricos, tal como tem sido apresentado e trabalhado tradicionalmente, e a segunda apresenta uma alternativa para superação da linearidade do estudo, considerando o uso da escala social de análise, por meio dos conceitos de espaço absoluto relativo e relacional, como elemento metodológico desenvolver uma aprendizagem significativa.

\footnotetext{
7 Outras pesquisas, nesse sentido, são realizadas com apoio da FAPERGS, PQ/CNPq, que são desenvolvidas pelo Grupo de pesquisa EMGEOCS que envolve acadêmicos de diversos níveis de ensino da graduação ao pósdoutorado.
} 


\section{Imagem 1 - Círculos Concêntricos}

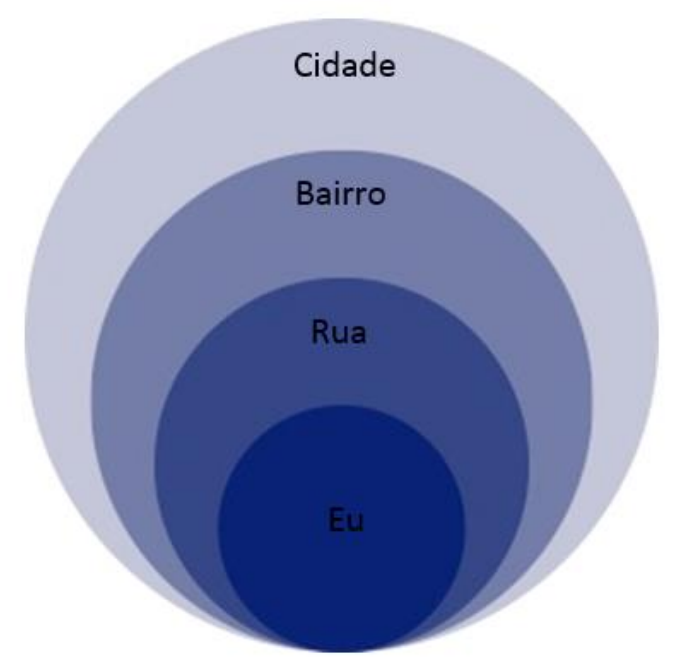

Fonte: As autoras.

\section{Imagem 2 - Espaço Absoluto, Relativo e Relacional}

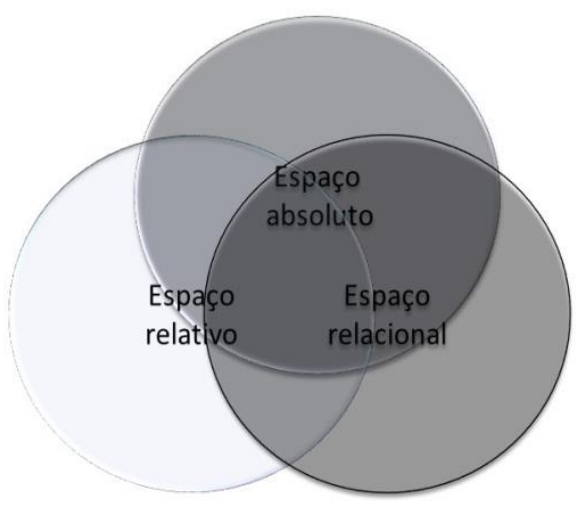

Fonte: Callai (2015, p. 39)

\section{O estudo do lugar}

Tomando os conceitos básicos da geografia, antes referidos que são: espaço, paisagem, território, região, lugar e tendo presente a ideia dos princípios, que ao longo da tradição da ciência geográfica são utilizados como referência para o estudo dessa ciência, interessa aqui centrar no conceito de lugar, pois este interliga com os demais conceitos e permite que o mundo da vida das crianças seja considerado no processo de aprendizagem. 
O lugar é um conceito e uma parte do espaço e, neste sentido, é o primeiro ponto a considerar num mundo que é globalizado com regramentos internacionais hegemônicos que se materializam em todos os lugares. Assim, não é possível pensar o lugar de forma isolada deste contexto maior que é a unidade terra. Isso envolve pensar o lugar não apenas como um ponto fixo no espaço, a sua localização, mas como um elo que diferencia e individualiza o lugar, e que o liga com os demais pontos da terra por meio das inter-relações que nele acontecem. Assim, é fundamental pensar o lugar na perspectiva das características que ele contém, e dos motivos que justificam essas características e daí ter a clareza de que "cada lugar é, à sua maneira o mundo [...] a história concreta do nosso tempo repõe a questão do lugar numa posição central” (SANTOS, 2014, p. 152).

Tendo essa lógica de entendimento, os conteúdos da geografia nos anos iniciais podem ser estudados a partir do lugar tendo-o como conceito e como conteúdo. E aí entra a diferença no encaminhamento metodológico para superar os círculos concêntricos, pois se cada lugar é a sua maneira o mundo, o encaminhamento metodológico não dispensa o cuidado com a escala de análise. A escala é o conceito que possibilita fazer a inter-relação entre os diversos níveis de análise. A sua utilização permite que nenhum fenômeno fique restrito ao âmbito do local em que está acontecendo, pois tudo que é universal se concretiza em um local, por isso nada ocorre de forma isolada no espaço. Ao mesmo tempo em que tudo é multidimensional, as pessoas materializam suas relações em determinados pontos do espaço, ou seja, no lugar, mas este "não pode ser compreendido em referência apenas ao que existe somente naquele ponto, ele depende de tudo ao que acontece ao redor dele" (HARVEY, 2012, p. 12).

Como proposição de estudo dos conteúdos, pode-se partir do EU tradicionalmente considerado, mas deste como ponto de referência para estabelecer as inter-relações com outros elementos do mundo, pois que cada aluno e suas famílias têm histórias próprias que não podem ser negligenciadas no processo de ensino. Então, partir do lugar para pensar o mundo 8 pode-se dar início ao estudo com o que é vivido no lugar, e também de algo de fora do lugar, mas que pode ser próximo do aluno em termos de

\footnotetext{
8 Essa discussão é apresentada no texto escrito por Callai, (2005, p. 227-247), Aprendendo a ler o mundo: a geografia nos anos iniciais do ensino fundamental.
} 
relações. Assim, pode-se partir de um problema que os alunos percebam no lugar onde vivem ou em seus arredores, e ao elaborar o problema, buscar as explicações internas (relativas ao próprio lugar) e externas (frutos de ações que são tomadas em contextos mais abrangentes e que repercutem de forma direta nos locais).

Tomemos como exemplo a cidade, mas pode ser o bairro, a rua, a escola e elaborar um problema que pode partir do conhecimento corriqueiro que os alunos trazem. Para buscar as respostas e as explicações têm que ser considerado o que tem no lugar, ou seja, quais as características internas que dão identidade ao lugar. Estas são as condições da natureza, das populações ali residentes, das questões sociais, econômicas, da cultura. Além destas, a localização e os entornos definidos pelos limites territoriais e as fronteiras que estabelecem as áreas de ligação entre os lugares, são dados significativos para a caracterização do lugar.

Elencar essas características e buscar explicações que remetam a responder o problema elaborado faz com que os alunos se posicionem sobre o assunto, e que coloquem em jogo a relação entre as suas experiências, ou seja, com os seus saberes prévios com relação aos novos saberes que serão conhecidos/construídos. Nesse contexto, é necessário o cuidado e atenção do professor com as narrativas a serem desenvolvidas pelos alunos.

Em resumo, considerando que o lugar pode ser o laboratório dos estudos, pois permite estudar e organizar as informações do mundo, tem-se a oportunidade de que desde cedo as crianças observem o seu espaço vivido para que possam conhecê-lo e compreendê-lo, no contexto das demandas maiores que são do mundo globalizado. Quando as crianças chegam à escola, elas trazem consigo as aprendizagens que adquiriram em sua vivência, que resultam das experiências que vão realizando, mas que não são tidas como sistemáticas. Por isso, o papel da escola desde os anos iniciais é conseguir articular o mundo empírico da criança com os conceitos científicos, pois assim como aprendemos a ler e a escrever é fundamental que as crianças consigam realizar a leitura de mundo, sempre fazendo referência ao seu mundo da vida. E não é demais pensar que a leitura e a escrita podem ser feitas a partir do lugar, espaço construído, que é o ambiente da vida comum dela, de sua família e seus amigos. 


\section{A geografia e as políticas públicas}

A escola funciona com seu aparato institucional estabelecido por um regramento nacional que decorre das orientações emanadas das políticas públicas. No contexto atual, a BNCC - Base Nacional Comum Curricular estabelece um conjunto de normativas que orientam o fazer escolar, expresso pelos currículos e pelos livros didáticos. No que se refere ao Livro Didático - existem os livros aprovados no PNLD, que trazem os conteúdos e atividades a serem realizadas e não podem ser descartados, pois trazem as informações que os professores vão utilizar nas aulas para desenvolver os conteúdos. Independente das reflexões que existem, e que mesmo nós também fazemos, inclusive com críticas, nosso entendimento a respeito dos Livros Didáticos é o que são aportes importantes para o trabalho do professor. Mas este não é o objeto de discussão aqui neste texto ${ }^{9}$.

A BNCC ao apresentar as orientações curriculares para a educação básica, em específico para os anos iniciais no contexto das Ciências humanas, afirma que a geografia articulada com a história, precisa se basear na ideia de que o ser humano produz o espaço em que vive, apropriando-se dele em determinada circunstância histórica. Acrescenta que cabe à geografia ensinar para "compreender o mundo em que se vive, na medida em que esse componente curricular aborda as ações humanas construídas nas distintas sociedades existentes nas diversas regiões do planeta" (BRASIL, 2018, p. 353).

Vejamos as sugestões e orientações de trabalho que são apresentadas tendo como pressuposto a educação geográfica, está

contribui para a formação do conceito de identidade, expresso de diferentes formas: na compreensão perceptiva da paisagem, que ganha significado à medida que, ao observá-la, nota-se a vivência dos indivíduos e da coletividade; nas relações com os lugares vividos; nos costumes que resgatam a nossa memória social; na identidade cultural; e na consciência de que somos sujeitos da história, distintos uns dos outros e, por isso, convictos das nossas diferenças (BRASIL, 2018, p. 359).

Aliado a isso, o documento apresenta as perguntas chave para o desenvolvimento da geografia nos anos iniciais: Onde se localiza?, Por que se localiza?, Como se distribui?, Quais as características sócio espaciais? (BRASIL, 2018, p. 367-368). Essas

\footnotetext{
${ }^{9}$ Os docentes que atuam nos anos iniciais têm uma formação geral a respeito de todas as disciplinas que fazem parte do currículo escolar, e por pesquisas não apenas de geografia, mas também das demais disciplinas pode-se reconhecer a precariedade dessa formação, diante do que o livro didático passa a ser fundamental.
} 
são questões que indicam o caráter espacial da geografia que precisam ser desenvolvidas desde esse nível de ensino. A localização é o ponto chave e ao mobilizar o olhar espacial, pretende remeter à observação e também a representação dos fenômenos espaciais. Isto posto, exige a atenção com a orientação e a escala de análise, e nas argumentações a serem desenvolvidas indica que se reconheça a dinâmica da natureza e as interferências humanas na superfície terrestre, conhecendo os lugares e estabelecendo conexões entre eles, sejam locais, regionais, territoriais ou mundiais.

De modo a dar conta dessas orientações que podemos considerar que são os aportes teóricos da geografia, que devem ser considerados na disciplina, a BNCC traz a proposição de trabalhar com os Princípios do Raciocínio Geográfico (BRASIL, 2018, p. 360) apresentados como: analogia, conexão, diferenciação, distribuição, extensão, localização, ordem. Estes, ao nosso entendimento, dizem das características da geografia e da importância de considerá-los, inclusive para superar no tratamento dos temas; a linearidade dos círculos concêntricos. Qualquer lugar estudado acolhe determinados fenômenos que por meio de uma organização espacial apresenta os arranjos possíveis a partir dos regramentos da sociedade que o produz. Veja-se que os fenômenos naturais fazem parte dessa estruturação que se caracteriza por uma complexidade na dinâmica dos próprios recursos naturais em sua feição e mecanismos de evolução diante das proposições dos homens que ali vivem. Mas ressalta-se que não são acasos e nem determinismos físicos, mas resultantes do jogo de forças que exige pensar no local e no global.

Trazendo exemplos de como estudar a cidade (lugar onde vivem os alunos), pode ser delimitada a rua ou o bairro, entre outros tendo os suportes metodológicos que expressam por meio do observar, descrever, interpretar, analisar compreender e representar. Assim sendo, propomos essas ferramentas metodológicas para desenvolver o estudo com qualquer fenômeno e recorte espacial que estuda a geografia. No caso interessa a proposição de estudar a cidade. 
Quadro 1 - Referenciais Metodológicos para o Ensino de Geografia

\begin{tabular}{|c|c|c|c|}
\hline Como fazer & 0 que fazer & $\begin{array}{c}\text { Utilização dos } \\
\text { princípios }\end{array}$ & $\begin{array}{l}\text { Exemplos de como } \\
\text { trabalhar a cidade }\end{array}$ \\
\hline Observar & $\begin{array}{l}\text { Planejar a observação: } \\
\text { 1. O que interessa observar, com } \\
\text { que tipos de olhar: qualquer coisa? } \\
\text { Tudo? Ou um problema que remete } \\
\text { a como observar. } \\
\text { 2. Que materiais são necessários } \\
\text { para realizar a observação. } \\
\text { 3. Quando será realizada a } \\
\text { observação? } \\
\text { 4. Definição do que será observado, } \\
\text { o espaço concreto, uma paisagem, } \\
\text { uma fotografia, ou um mapa que } \\
\text { represente a cidade. }\end{array}$ & $\begin{array}{l}\text { Localização } \\
\text { Diferenciação } \\
\text { Distribuição } \\
\text { Extensão }\end{array}$ & $\begin{array}{l}\text { Um problema existente na } \\
\text { cidade, bairro, rua. } \\
\text { 1. As rápidas } \\
\text { transformações da } \\
\text { paisagem da minha cidade. } \\
\text { Como era? Como está } \\
\text { atualmente? } \\
\text { 2. Ouvir histórias ou mesmo } \\
\text { coletar relatos de pessoas } \\
\text { mais antigas. Observar em } \\
\text { imagens, fotografias } \\
\text { antigas, mapas, entre } \\
\text { outros. } \\
\text { 3. Definir a temporalidade a } \\
\text { partir de quando a cidade } \\
\text { foi criada até os dias atuais. } \\
\text { Se passaram quanto tempo? } \\
\text { 4. Podem ser analisadas as } \\
\text { ruas, formatos das casas, os } \\
\text { serviços oferecidos e a } \\
\text { localização desses serviços } \\
\text { (como era e como ficou?). }\end{array}$ \\
\hline Descrever & $\begin{array}{l}\text { É a organização do que foi e/ou } \\
\text { está sendo observado. É o momento } \\
\text { de organizar e sistematizar os } \\
\text { fragmentos num contexto que } \\
\text { permita perceber os fundamentos e } \\
\text { significados de estudar aquele } \\
\text { determinado lugar. }\end{array}$ & $\begin{array}{c}\text { Analogia } \\
\text { Conexão } \\
\text { Ordem } \\
\text { Extensão }\end{array}$ & $\begin{array}{l}\text { A descrição dessas } \\
\text { transformações poderá ser } \\
\text { realizada por meio de } \\
\text { desenhos, relatos, escritos } \\
\text { que mostrem a imaginação } \\
\text { dos alunos sobre a sua } \\
\text { percepção de como era a } \\
\text { cidade. }\end{array}$ \\
\hline Interpretar & $\begin{array}{l}\text { É buscar os entendimentos do que } \\
\text { foi observado e está descrito. Ao } \\
\text { interpretar os alunos produzem as } \\
\text { argumentações tendo as bases dos } \\
\text { seus conhecimentos prévios, das } \\
\text { experiências e verificados com os } \\
\text { conceitos científicos. As bases } \\
\text { teóricas. } \\
\text { Interpretar pode se caracterizar } \\
\text { como desvelar o oculto, tornar } \\
\text { visível aquilo que ainda não o é. }\end{array}$ & $\begin{array}{l}\text { Analogia } \\
\text { Conexão } \\
\text { Ordem }\end{array}$ & 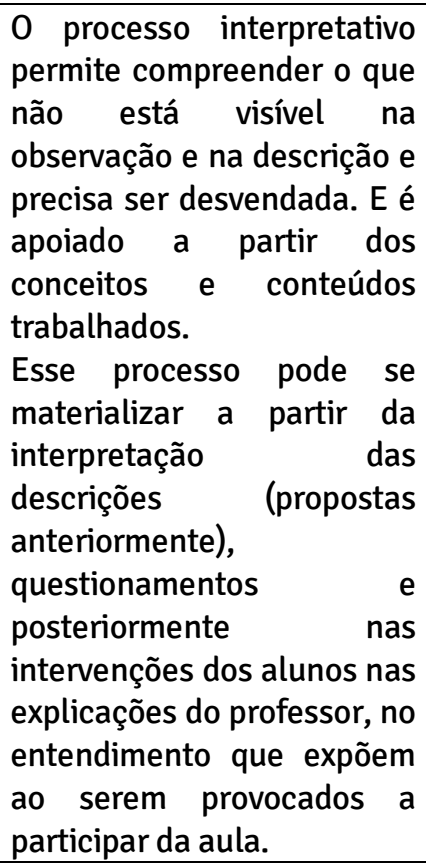 \\
\hline Analisar & $\begin{array}{l}\text { Analisar supõem decodificar o que } \\
\text { foi feito até o momento e organizar } \\
\text { "os pedaços juntando num processo }\end{array}$ & $\begin{array}{c}\text { Analogia } \\
\text { Conexão } \\
\text { Diferenciação }\end{array}$ & $\begin{array}{l}0 \text { processo analítico ocorre } \\
\text { quando os alunos } \\
\text { conseguem entender as }\end{array}$ \\
\hline
\end{tabular}




\begin{tabular}{|c|c|c|c|}
\hline & $\begin{array}{l}\text { de sistematização. É juntar os } \\
\text { conhecimentos prévios, com o que } \\
\text { resulta das experiências e } \\
\text { considera no confronto dos } \\
\text { conceitos científicos. } \\
0 \text { processo de análise supõe } \\
\text { perceber os fragmentos, fazer as } \\
\text { sínteses e verificar os significados } \\
\text { de cada uma das questões } \\
\text { observadas diante do contexto mais } \\
\text { amplo. A escalaridade passa a ser } \\
\text { fundamental nesse processo. }\end{array}$ & $\begin{array}{c}\text { Distribuição } \\
\text { Extensão }\end{array}$ & $\begin{array}{l}\text { relações existentes entre as } \\
\text { diferentes paisagens e } \\
\text { espaços, ao mesmo tempo } \\
\text { percebem as paisagens são } \\
\text { diferentes nos diversos } \\
\text { lugares, mas que possuem } \\
\text { elementos similares, entre } \\
\text { eles as suas as formas e as } \\
\text { funções. } \\
\text { Ocorre quando os alunos } \\
\text { expressam a sua opinião, ou } \\
\text { entendimento acerca do } \\
\text { fenômeno a partir daquilo } \\
\text { que observam e descrevem. }\end{array}$ \\
\hline Compreender & $\begin{array}{l}\text { Decorre da possiblidade de indagar, } \\
\text { de questionar, de elaborar novas } \\
\text { interpretações sempre tendo em } \\
\text { consideração o contexto em que } \\
\text { está a questão considerada. A } \\
\text { compreensão se constrói numa } \\
\text { rede de significados envolvendo os } \\
\text { conhecimentos prévios dos } \\
\text { estudantes e considerando o que } \\
\text { está sendo produzido a partir do } \\
\text { processo empírico de observar, } \\
\text { tendo os referenciais teóricos que } \\
\text { podem sustentar os entendimentos } \\
\text { e modo científico. }\end{array}$ & $\begin{array}{c}\text { Conexão } \\
\text { Ordem }\end{array}$ & $\begin{array}{llr}\text { A compreensão pode } & \text { por a } \\
\text { ocorrer a partir da } \\
\text { intervenção e proposição } \\
\text { dos alunos de como } \\
\text { melhorar o problema } \\
\text { encontrado, } & \text { propondo } \\
\text { soluções a este. } & \end{array}$ \\
\hline Representar & $\begin{array}{l}\text { É produzir narrativas e o primeiro } \\
\text { ponto é esclarecer qual a pergunta } \\
\text { que está sendo motivação para ser } \\
\text { respondida e então, considerando } \\
\text { os processos indicados } \\
\text { anteriormente, encaminhar aquilo } \\
\text { que pode ser o resultado do } \\
\text { aprendido até então. Essa } \\
\text { representação, embora possa ser de } \\
\text { variadas formas, no caso da } \\
\text { geografia, acontece } \\
\text { frequentemente com a elaboração } \\
\text { de textos, montagem de tabelas } \\
\text { informativas e de gráficos e, de } \\
\text { modo específico, como linguagem } \\
\text { da geografia pelos mapas. }\end{array}$ & $\begin{array}{c}\text { Distribuição } \\
\text { Extensão }\end{array}$ & $\begin{array}{l}\text { A representação pode-se } \\
\text { dar de diferentes formas de } \\
\text { linguagem, como croqui, } \\
\text { desenho, mapa, textos, } \\
\text { poemas, relatos, } \\
\text { fotografias, desenhos de } \\
\text { paisagens, produção de } \\
\text { vídeos, montagem de peças } \\
\text { de teatros, organização de } \\
\text { exposições com o material } \\
\text { produzido, de forma a } \\
\text { propor a melhoria ou } \\
\text { solução para o problema } \\
\text { inicialmente determinado. }\end{array}$ \\
\hline
\end{tabular}

Fonte: As autoras.

\section{A geografia e formação para a cidadania}

As proposições da BNCC no seu conjunto consideram que as Ciências Humanas precisam estimular a formação ética como elemento imprescindível para formação das novas gerações, afim de que os estudantes valorizem “os direitos humanos; o respeito 
ao ambiente e à própria coletividade; o fortalecimento de valores sociais, tais como a solidariedade, a participação e o protagonismo voltados para o bem comum; e, sobretudo, a preocupação com as desigualdades sociais” (BRASIL, 2018, p. 354).

Neste contexto, a geografia, que é uma das disciplinas deste complexo que é apresentado na BNCC como as Ciências Humanas, tem um papel, considerando o seu fazer específico que é a partir de suas bases teóricas e encaminhamentos metodológicos. Este papel é estudar o mundo com o olhar geográfico, tendo o pensamento geográfico como o elo para os entendimentos da realidade estudada.

Os conteúdos da geografia para os anos iniciais estão conectados com a disciplina de geografia no contexto dos currículos escolares para a educação básica. Nesta perspectiva, existe um conjunto de conhecimentos do senso comum que decorrem das experiências vividas e do seu fazer cotidiano. Este conhecimento não pode ser desconhecido, e na escola eles se contrapõem ou se agregam, dependendo das circunstâncias, aos conhecimentos científicos que têm suas bases na produção científica da humanidade e que são expressos pelos conceitos.

Este é o conhecimento que a escola trabalha, que compõem os currículos, que estão apresentados nos livros didáticos, o que Young (2007) chama de conhecimento poderoso. 0 autor propõe que pensemos a relação entre o conhecimento formal, ou seja, aquele adquirido na escola, e o conhecimento não formal, aquele que pode ser aprendido no convívio social. Para isso, aponta dois tipos de conhecimento: o primeiro é o "conhecimento dependente do contexto" ou "conhecimento procedimental", este "se desenvolve ao se resolver problemas específicos no cotidiano" (YOUNG, 2007, p. 1296). O segundo é o "conhecimento independente do contexto" ou "conhecimento teórico". Esse conhecimento é geralmente relacionado às ciências de alta complexidade e é potencialmente aquele adquirido nas escolas, o conhecimento poderoso (YOUNG, 2007, p. 1297).

Como fazer o entrelaçamento entre estes conhecimentos de modo a que se oportunize ao aluno a construção das bases para seus aprendizados? A geografia nos anos iniciais tem sido provocada a dar essas bases para que, a partir dos anos finais do Ensino Fundamental, os alunos possam trabalhar com os conceitos e compreender a realidade do mundo tendo o acesso aos conhecimentos que o tornam um sujeito com autonomia de pensamento e capacidade de sustentação de uma atitude de cidadania. É 
nesse sentido que o duplo papel da geografia nos anos iniciais é, além de dar as bases para os aprendizados futuros da geografia, também o de contribuir com o processo de alfabetização de modo que a leitura da palavra e a sua escrita tenham significados para suas vidas para além delas mesmas.

Essas duas condições postas ao ensino da geografia (tendo as demais disciplinas também com este intuito) pode encaminhar para uma formação cidadã. Essa perspectiva nos remete a pensar em um ensino que tenha em vista a elaboração, compreensão e entendimento a partir de problemas que são do mundo da vida. "Assim, pois, educar tem que ser, sobretudo, preparar para participar na gestão dos graves problemas atuais do nosso mundo e para comprometer-se como cidadãos e cidadãs, em sua solução"10”. (GARCÍA PÉREZ, 2015, p. 13).

Num esforço de buscar argumentos para um ensino nessa perspectiva, consideramos que é importante que o professor tenha clareza em seu planejamento das seguintes questões: Para quem? Quando? Para que? O que? Como?

No caso dessa discussão, tomamos como ponto de partida o Para quem?, que diz dos alunos dos anos iniciais que estão sendo alfabetizados e dando início a sua formação escolarizada na educação básica. Ligado a esta questão está o Quando? que diz do momento da escolarização em que o aluno está adentrando ao mundo da leitura e da escrita como condição para seus aprendizados. Sendo estes os alunos e este o momento, a pergunta Para quê? tende a responder qual o papel da geografia neste período escolar. E a resposta diria: para que o aluno aprenda ao ler lendo o mundo da vida de modo a compreender os problemas e as realidades que estamos vivendo nos tempos atuais. Ao ensinar geografia, lendo o mundo, habilita os alunos a construírem conceitos que explicam teoricamente aqueles conteúdos que corriqueiramente são conhecidos. Este é o que, que são os conteúdos que reportam ao mundo próximo dos alunos, por isso o estudo da cidade, do bairro, da rua, da escola, do ambiente familiar é essencial. Enfim, do lugar com suas histórias. 0 Como? se caracteriza pelas estratégias e metodologias adotadas, que estando de acordo com as respostas às perguntas dos outros elementos estabelece os caminhos que se sustentam teoricamente numa postura de formação de um pensamento autônomo de um sujeito que compreenda a sua realidade, quer dizer, o seu mundo de um modo crítico.

${ }^{10}$ Tradução livre das autoras. 
No caso da geografia, que aprenda desde logo que os espaços são construídos pelos homens no seu fazer cotidiano, tendo as referências de que tipo de sociedade e dos modos como os grupos sociais se organizam no seu interior. Daí que as questões da natureza (da geografia física) precisam ser abordadas em suas concepções científicas e compreendendo-as não como determinantes de problemas ambientais (por exemplo), mas como problemas que resultam das questões sociais, culturais e econômicas.

\section{A escala de análise: a relação entre o local e o global}

Existe um conjunto de conceitos que permitem pensar a totalidade a partir de recortes espaciais, que já foram apresentados neste texto: lugar, região, paisagem e território. Eles possibilitam, juntamente com ferramentas metodológicas, aprender a pensar e ler o espaço para posteriormente compreendê-lo. Contudo, essa não é uma tarefa fácil, pois exige do professor um domínio teórico conceitual para encaminhar as atividades com seus alunos.

Todavia, salientamos que é impossível desenvolver a leitura de mundo sem trabalhar os conceitos de forma articulada. Eles só existem e se tornam essenciais para a leitura de mundo na sua relação, pois nenhum fenômeno no mundo ocorre de forma isolada. Assim, como é impossível pensar o mundo apenas pela dimensão física ou pela dimensão humana, é impossível pensar a geografia sem os seus recortes espaciais, pois eles permitem e oportunizam estudos com maior grau de acuidade dos fenômenos. É nesse sentido, que emerge o conceito de escala de análise, que na geografia permite que o entendimento da relação entre os fenômenos e níveis de análise.

Dessa forma, tornam- se "necessárias interligações dos vários níveis de análise, para que se possa compreender que nada acontece por acaso e que os motivos de muitos acontecimentos podem estar, às vezes, próximos, mas podem estar também muito distantes” (CALLAI, 2005, p. 239). É a escala de análise que oportuniza este exercício de reflexão e produz entendimentos dos problemas sociais que são territorialidades, que fazem no espaço a materialização dos processos humanos na sua relação da sociedade com a natureza. E esta é a perspectiva que supera a ideia de ensinar pelos círculos concêntricos.

Todos os fenômenos ocorrem em determinado local no espaço (espaço absoluto/fixo), isto é, possui uma localização que precisa em termos de latitude e 
longitude, de orientação dos pontos cardeais. Contudo, esse local, lugar, só pode ser entendido se relacionado com outros lugares (outras escalas/recortes), para que assim sejam dados as suas similaridades e diferenças. Cada lugar possui características que lhes são específicas e se desenvolvem de acordo com as características físico-naturais e socioculturais. Outra questão, importante é entender a temporalidade, o que do passado se materializa no presente e o que do presente poderá acarretar mudanças para o futuro. Tudo isso, permite ver que o espaço muda, conforme muda o recorte e conforme a temporalidade, por isso ele (espaço) é relativo.

Ao estudar a cidade, elegendo como problemática a transformação da paisagem da cidade, um fator essencial é buscar despertar na criança a sua imaginação, e a imaginação pode ser desenvolvida a partir do conto de histórias sobre como era a sua cidade. As crianças podem ir imaginando, criando representações simbólicas de como era a cidade que moram atualmente, há anos. 0 professor pode pedir que as crianças representem, por meio de desenhos, alguma passagem da história, ou do que acharem interessante. Os alunos podem perguntar aos seus pais, avós, vizinhos ou pessoas próximas como era a cidade em sua época de criança. Em um momento posterior, o professor pode levar diversas imagens antigas que mostrem como era a cidade. Pode haver um momento de socialização entre os desenhos e as fotos trazidas pelo professor. E, a partir delas, introduzir as questões: 0 que mudou? 0 que permanece igual ou parecido? 0 que fez com que a cidade mudasse ao longo do tempo? Quais as mudanças ocasionadas no modo de vida das pessoas? Como era o processo de deslocamento e comunicação?

As imagens vão remeter à memória e às recordações da cidade, ou seja, representam o passado, e as transformações que ocorreram ao longo do tempo, pois nada é estático. As imagens irão mostrar as diferentes formas da cidade, os ângulos das ruas, como eram as casas, estabelecimentos sociais, meios de transporte, comunicação. Em seguida pergunte: $E$ a localização da cidade mudou? E a localização das coisas representadas nas imagens? Peça que as crianças descrevam suas percepções, e caso os lugares de algum fenômeno tenham mudado, peça que elas analisem e escrevam o porquê dessa mudança. Ex: 0 mercado não é mais no mesmo local. 0 professor pode com auxílio do mapa do Estado e do município ir construindo 
um mapa mental com as diferentes localizações. Essa atividade envolve a observação e a descrição dos fenômenos.

Em seguida, peça aos alunos que analisem se a extensão da sua cidade mudou, ou seja, quantas ruas a sua cidade tinha na época em que as fotos foram tiradas? $E$ quantas têm hoje? Pode-se perceber o quanto os limites da cidade foram se expandindo e isso envolve as medidas do terreno. A extensão da cidade, se ela é grande, média ou pequena, vai envolver o uso de mais ou menos recursos naturais, mais infraestrutura para atender as demandas populacionais, 0 estabelecimento de regras para planejamento e uso desse território. Um mapa antigo e um mapa atual da cidade podem ajudar nesse processo. Mas além da extensão, existem peculiaridades que são específicas de cada cidade, como; o lugar onde o sol nasce e se põe, o clima, a temperatura, a vegetação, as águas, os ventos, o formato das casas, das ruas, os tipos de comércio, as indústrias, os serviços, o trânsito, um ponto turístico, enfim, cada cidade possui e tem diversas características específicas e com isso também possui diversas funções.

Nesse sentido, podemos dizer que todas as cidades em qualquer lugar do mundo possuem elementos análogos, pois uma cidade é sempre permeada de um espaço urbano, entre outros meios e serviços que não são encontrados na zona rural, mas também de singularidades específicas, como o exemplo apresentado. Assim, os princípios da diferenciação e da conexão ajudam as crianças a perceberem a transformação da paisagem, especialmente aqueles que nunca saíram ou tiveram a oportunidade de sair da sua cidade, o que conhece da sua cidade, quem dela nunca saiu? (BROEK, 1981).

Ainda, pode-se indagar aos alunos: será que as normatizações (regras) que temos hoje, como por exemplo, o uso e apropriação dos diferentes espaços, as regras de trânsito, entre outras eram as mesmas de quando a cidade teve início? Pode-se pedir que as crianças conversem com seus pais, avós, vizinhos ou parentes próximos para entender como tudo funcionava. É interessante analisar com os alunos, que para vivermos harmonicamente em sociedade foi preciso a criação de leis, decretos, formas de sinalizações, placas que indicam como pode ocorrer o uso de determinado espaço, tudo isso organiza a forma como vivemos e convivemos. Muitas vezes, as normatizações 
envolvem significativa interpretação dos alunos, pois muitas vezes ela não está visível, precisa ser desvendada.

Por fim, o uso de imagens atuais dos mesmos lugares antigos propondo que os alunos interpretem o que mudou na paisagem. A partir do exposto, os alunos podem analisar a sua cidade a partir do que foi trabalhado e, em seguida, o professor pode propor para que os alunos expressem, por meio de desenhos, ou fotografias da cidade o que mudariam, ou que gostariam que tivesse na sua cidade (deixando a imaginação deles voar), que outras normatizações criariam para uso do espaço. 0 processo de compreensão é uma forma superior de pensamento e é desenvolvido em consonância com a imaginação, com a percepção/observação/análise e representação dos fenômenos.

\section{Considerações Finais}

A geografia é uma área do conhecimento que pode contribuir para a construção de sujeitos capazes de identificar, contextualizar, analisar e interpretar os fenômenos da vida pessoal e social no âmbito local e global, instigando-o a interagir com vistas à transformação social.

A nossa proposição do ensino de Geografia para os anos iniciais, é centrar os conteúdos na cidade que é o lugar onde vivem as crianças, para que seja desenvolvida a leitura do mundo. E assim, a geografia fornece conteúdos para desencadear os processos da alfabetização do aprender a ler e escrever o mundo da vida, tendo o espaço como o objeto do estudo. Como premissa desta condução metodológica está a escala de análise, recurso que permite fazer a inter-relação entre os fenômenos naturais e humanos, nos espaços onde ocorrem e nas suas interligações com os demais lugares. Espaços por vezes mais distantes, mas aproximados por interesses que podem ser de vários níveis: econômicos, sociais, culturais, pessoais, familiares etc. Estabelecem-se, portanto, os vínculos entre o local e o global na medida em que as explicações e motivações dos fenômenos ocorridos em cada lugar têm interligação com os demais lugares e com o todo.

Consideramos, assim, que o papel da geografia nas séries iniciais é aprender a pensar o espaço tendo como centralidade o lugar vivido. Este conceito traz em si a ideia de totalidade, ou seja, de todas as coisas do mundo, que vão desde os fenômenos 
físicos aos humanos, aos fenômenos sociais e aos culturais. Por estes caminhos, as palavras se constituem a expressão possível do que existe na realidade e o aluno lê o mundo ao mesmo tempo em que lê as palavras. Desenvolve a observação dos elementos que são parte do mundo a partir das formas que são aparentes, associando as formas e os significados, usando símbolos para descrever o que compõem a identidade dos lugares. É perguntar-se sobre onde estão as coisas, é localizar os fenômenos, perceber as distribuições (das pessoas, dos pontos de trabalho, de lazer, as praças, as igrejas, os clubes, o comércio). E é identificar tudo isso no contexto de uma rede de significados, elaborando as interpretações e fazendo as sistematizações, passando assim a refletir acerca do significado das vivências humanas nesses lugares.

Ler e escrever, portanto, têm a ver com compreender pela linguagem as características do mundo, sistematizando as informações e organizando-as em conhecimentos que fazem a interface entre o lugar, o mundo e a vida comum. Ser alfabetizado aprendendo a ler e escrever o mundo da vida pode ser mais significativo para o aluno ao dar os sentidos para além das palavras soltas. As narrativas estabelecem os elos, e permitem que o aluno inicie a sua escolarização com bases científicas, entrelaçando com a vida vivida expressa pelos conhecimentos do senso comum. Dar sentido à palavra pode favorecer o aluno a aprender dar sentido para o que vive.

\section{Referências}

BRASIL. Ministério da Educação. Base Nacional Comum Curricular. Brasília: MEC: CONSED: UNDIME, 2018.

BROEK, J. Iniciação ao estudo da geografia. 4. ed. Rio de Janeiro: Zahar, 1981.

CALLAI, H. C. A questão da cidadania nas séries iniciais. In: CALLAI, H. C.; TOSO, C. E. I. (org.). Diálogos com professores. cidadania e práticas educativas. ljuí: Ed. UNIJUÍ, 2015. p.23-42.

CALLAI, H. C. Aprendendo a ler o mundo: a geografia nos anos iniciais do ensino fundamental. Caderno Cedes, Campinas, v. 25, n. 66, p. 227-247, maio/ago. 2005. Disponível em: http://www.scielo.br/pdf/ccedes/v25n66/a06v2566.pdf. Acesso em: mar. 2020.

GARCÍA PÉREZ, F. F. Puede la enseñanza de la geografía promover la educación ciudadana?. In: RABELO, C. P. S.; BUENO, M. A. Currículo: políticas públicas e ensino de geografia. Goiânia: Editora da PUC, 2015. p. 15-33. 
GONÇALVES, T. R. P. S. Alfabetização geográfica: o olhar dos educadores geográficos de universidades públicas brasileiras. 2013. Dissertação (Mestrado) - Universidade Federal de Juiz de Fora, Juiz de Fora, 2013.

HARVEY, D. 0 espaço como palavra-chave. GEOgraphia, Niterói, v. 14, n. 28, p. 8-39, 2012.

HEIDRICH, A. L.; HEIDRICH, B. B. Reflexões sobre o estudo do território. In: BUITONI, M. M. S. Geografia: ensino fundamental. Brasília: MEC, 2010. p. 113- 136.

KUHN, M.; CALLAI, H. C.; TOSO, C. E. I. Pressupostos epistemológicos dos círculos concêntricos. Revista e-Curriculum, São Paulo, v. 17, n. 2, p. 472-491, abr./jun. 2019.

TOSO, C. E. I.; KUHN, M.; CALLAI, H. C. O ensino dos estudos sociais nos anos iniciais da educação básica e os círculos concêntricos. Para Onde!?, Porto Alegre, v. 10, n. 1, p. 220-227, 2018. Edição especial.

MORAES, A. C. R. Geografia pequena história crítica. 20. ed. São Paulo. Annablume, 2000.

SANTOS, M. Metamorfose do espaço habitado. São Paulo: Hucitec, 1988.

SANTOS, M. A natureza do espaço: técnica e tempo, razão e emoção. São Paulo: Edusp, 2014.

YOUNG, M. F. D. Para que servem as escolas?. Educação e Sociedade, Campinas, v. 8, n. 101, p. 1287-1302, set./dez. 2007.

YOUNG, M. F. D. O futuro da educação em uma sociedade do conhecimento: o argumento radical em defesa de um currículo centrado em disciplinas. Revista Brasileira de Educação, Rio de Janeiro, v. 16, n. 48, p. 609-623, set./dez. 2011. 